\title{
Platelet Counts and Patent Ductus Arteriosus in Preterm Infants: A Systematic Review and Meta-Analysis
}

\author{
Sorina R. Simon ${ }^{\mathrm{a}} \quad$ Lieke van Zogchel $^{\mathrm{a}} \quad$ Maria Pilar Bas-Suárez $^{\mathrm{b}}$ \\ Giacomo Cavallaro $^{c}$ Ronald I. Clyman ${ }^{d}$ Eduardo Villamor ${ }^{a}$ \\ aDepartment of Pediatrics, Maastricht University Medical Center (MUMC+), School for Oncology and Developmental \\ Biology (GROW) and Cardiovascular Research Institute Maastricht (CARIM), Maastricht, The Netherlands; \\ ${ }^{b}$ Department of Pediatrics, Hospital Universitario Materno-Infantil de Canarias, Las Palmas de Gran Canaria, Spain; \\ 'Neonatal Intensive Care Unit, Department of Clinical Sciences and Community Health, Fondazione IRCCS Cà \\ Granda Ospedale Maggiore Policlinico, Università degli Studi di Milano, Milan, Italy; ${ }^{\mathrm{d} C a r d i o v a s c u l a r ~ R e s e a r c h}$ \\ Institute and Department of Pediatrics, University of California San Francisco, San Francisco, Calif., USA
}

\section{Key Words}

Platelets · Ductus arteriosus · Meta-analysis

\begin{abstract}
Background: Several cohort studies have shown an association between low platelet counts in the first day(s) of life and patent ductus arteriosus (PDA) in preterm infants. However, these results have not been confirmed by other studies. $\mathbf{O b}$ jective: To perform a meta-analysis of all the studies addressing the relationship between platelet counts in the first day(s) of life and PDA in preterm infants. Methods: PubMed/MEDLINE and EMBASE were searched from their inception until December 2014. Results from 11 cohort studies involving 3,479 preterm infants (gestational age $<32$ weeks) were pooled using random-effects modeling. Results: Meta-analysis showed a significant positive association between PDA and platelet counts $<150 \times 10^{9} /$ [ [6 studies, risk ratio $(\mathrm{RR})=$ 1.215, 95\% Cl: 1.027-1.436], between PDA and platelet counts $<100 \times 10^{9} / \mathrm{I}(5$ studies, $\mathrm{RR}=1.255,95 \% \mathrm{Cl}$ : $1.034-$ 1.525), and between significant PDA (SPDA) and platelet counts $<100 \times 10^{9} / \mathrm{I}(5$ studies, $\mathrm{RR}=1.254,95 \% \mathrm{Cl}$ : $1.021-$
\end{abstract}

1.540). The association between SPDA and platelet counts $<150 \times 10^{9}$ /I was not statistically significant ( 6 studies, RR = 1.289 , 95\% Cl: 0.925-1.795). Pooled standard differences in mean platelet counts between infants with and without PDA/SPDA were not statistically different. Conclusion: This meta-analysis reveals a marginal but significant association between low platelet counts in the first day(s) of life and PDA/ SPDA in very preterm infants. This association needs to be confirmed in prospective studies.

(c) 2015 S. Karger AG, Basel

\section{Introduction}

Despite decades of clinical and basic science progress, the persistence of a patent ductus arteriosus (PDA) in very preterm infants is still presenting important challenges in terms of pathobiology, assessment, clinical consequences, and management [1-6]. Recently, Echtler et al. [7] demonstrated that activated platelets adhered to and accumulated in the lumen of the constricted mice ductus arteriosus (DA) within minutes after birth. More-

\section{KARGER 125}

(c) 2015 S. Karger AG, Base

$1661-7800 / 15 / 1082-0143 \$ 39.50 / 0$

E-Mail karger@karger.com

www.karger.com/neo
Eduardo Villamor, $\mathrm{MD}, \mathrm{PhD}$

Department of Pediatrics

Maastricht University Medical Center (MUMC+)

P. Debyelaan 25, PO Box 5800, NL-6202 AZ Maastricht (The Netherlands)

E-Mail E.Villamor@mumc.nl 
Table 1. Characteristics of the studies included in the meta-analysis

\begin{tabular}{|c|c|c|c|c|c|c|c|c|c|c|c|}
\hline First author [Ref.] & Year & $\mathrm{n}$ & $\begin{array}{l}\text { GA } \\
\text { cohort, } \\
\text { weeks }\end{array}$ & $\begin{array}{l}\text { BW } \\
\text { cohort, } \\
\text { g }\end{array}$ & $\begin{array}{l}\% \\
\text { males }\end{array}$ & $\begin{array}{l}\text { PDA } \\
\text { assessment, } \\
\text { day of life }\end{array}$ & $\begin{array}{l}\% \\
\text { PDA }\end{array}$ & $\begin{array}{l}\% \\
\text { SPDA }\end{array}$ & $\begin{array}{l}\text { Range PL } \\
\text { assessment, } \\
\text { days }\end{array}$ & $\begin{array}{l}\% \mathrm{PL} \\
<150\end{array}$ & $\begin{array}{l}\% \mathrm{PL} \\
<100\end{array}$ \\
\hline Fujioka [11] & 2011 & 118 & 27.9 & 1,059 & 57.6 & $3-5$ & 29.7 & $23.7^{\mathrm{a}}$ & 1 & 16.1 & $6.8^{\mathrm{a}}$ \\
\hline Shah [12] & 2011 & 497 & 25.8 & 825 & 52.6 & 3 & 34.0 & NR & 3 & $27.2^{\mathrm{a}}$ & $8.7^{\mathrm{a}}$ \\
\hline Dwarakanath [19] ${ }^{\mathrm{b}}$ & 2011 & 148 & 26.0 & 733 & 50.0 & NR & 60.8 & $45.9^{c}$ & 3 & 41.2 & NR \\
\hline Sallmon [13] & 2012 & 1,350 & 28.3 & 1,060 & 48.7 & $4-5$ & 56.3 & 26.7 & 1 & 16.44 & 3.4 \\
\hline Dani [10] & 2012 & 163 & 27.1 & 931 & 49.7 & $1-2$ & NR & 82.8 & 1 & 32.5 & $19.6^{\mathrm{a}}$ \\
\hline Brunner [18] & 2013 & 322 & 29.0 & 1,170 & 50.6 & $2-7$ & 50.9 & 47.2 & 1 & NR & $2.8^{\mathrm{d}}$ \\
\hline Bas-Suárez [15] & 2014 & 194 & 27.9 & 1,008 & 55.7 & $2-4$ & NR & 54.6 & 2 & 11.3 & 6.7 \\
\hline Chen [14] & 2014 & 77 & 29.5 & 1,153 & 49.4 & $3-6$ & NR & 44.2 & 1 & NR & NR \\
\hline CPS $^{e}$ & 2015 & 126 & 28.4 & 1,096 & 51.2 & $2-4$ & 69.8 & 64.3 & 2 & 28.57 & 14.28 \\
\hline
\end{tabular}

In the study of Shah et al. [12], all the patients received prophylactic indomethacin. In the study of Echtler et al. [7], a nonreported number of patients received prophylactic indomethacin. GA = Gestational age (mean or median); BW = birth weight total cohort (g, mean or median); $\mathrm{PL}=$ platelets $\left(\times 10^{9} / \mathrm{l}\right) ; \mathrm{NR}=$ data not reported. ${ }^{\text {a }}$ Data not reported in the original article but obtained after request to authors. ${ }^{\mathrm{b}}$ Abstract. ${ }^{\mathrm{c}}$ Based on number of patients treated with COX inhibitors. ${ }^{\mathrm{d}}$ Patients with platelet count $<50 \times 10^{9} / 1$ were excluded. ${ }^{e}$ Unpublished multicenter study, Carbamoyl Phosphate Synthetase (CPS) Polymorphisms as Risk Factor for Necrotizing Enterocolitis.

over, mice with defective platelet adhesion or biogenesis had high rates of PDA [7]. Thus, platelets may be crucial for mice DA closure by promoting thrombotic sealing of the constricted DA and luminal remodeling [7]. However, whether this is also the case in human infants remains controversial $[1,8]$.

Echtler et al. [7] also performed a retrospective, multivariable analysis in a cohort of 123 infants born at 24-30 weeks of gestation. They reported that a platelet count between 101 and $140 \times 10^{9} / 1$ on the first day of life was an independent predictor of PDA. Since the publication of this study, several additional cohorts have been reported with discordant results [9-15]. We performed a metaanalysis of all the studies reported to date addressing the association between platelet counts in the first day(s) of life and the presence of a PDA in preterm infants, in an attempt to clarify this issue.

\section{Methods}

A protocol was developed prospectively that detailed the specific objectives, criteria for study selection, approach to assessing study quality, clinical outcomes, and statistical methodology.

\section{Sources}

A comprehensive literature search was undertaken using the PubMed/MEDLINE, and EMBASE databases from their inception to December 1,2014. The search terms involved various combinations of the following keywords: 'ductus arteriosus', 'patent ductus arteriosus', 'PDA', 'platelet(s)', 'platelet count(s)', and 'thrombocytopenia'. We searched the Science Citation Index and Google Scholar for articles citing the studies identified by our electronic searches.

\section{Study Selection}

Three investigators (S.R.S., M.P.B.-S., and E.V.) independently evaluated studies for inclusion and any disagreements were resolved by discussion. Studies were included if they had a comparison group, examined preterm infants, and reported primary data that could be used to measure the association between PDA and platelet counts.

\section{Data Extraction and Assessment of Study Quality}

Two investigators (S.R.S. and M.P.B.-S.) independently extracted data on study design, study quality, demographics (table 1), rate of PDA and/or significant PDA (SPDA), and platelet counts. A third reviewer (E.V.) checked the data extraction for completeness and accuracy. In cases in which necessary data were missing from the studies, additional information was requested from the authors. Methodological quality was assessed using the Newcastle-Ottawa Scale (NOS) for cohort studies [16]. This scale uses a star rating system (range: 0-9 stars) scoring three aspects of the study: selection (0-4), comparability (0-2), and outcomes (0-3).

\section{Statistical Analysis}

Studies were combined and analyzed using Comprehensive Meta-Analysis v. 2.0 software (Biostat Inc., Englewood, N.J., USA). The effect measures estimated were risk ratio (RR) for dichotomous outcomes, and standard mean difference for continuous
Simon/van Zogchel/Bas-Suárez/ Cavallaro/Clyman/Villamor 
Table 2. Risk factors for the development of PDA/SPDA

\begin{tabular}{|c|c|c|c|}
\hline First author [Ref.] & Significant risk factors on multivariable analysis & Odds ratio & $95 \% \mathrm{CI}$ \\
\hline Echtler [7] & platelet count $<150 \times 10^{9} / 1$ & 13.13 & $3.47-49.60$ \\
\hline Shah [12] & $\begin{array}{l}\text { absolute platelet nadir } \\
\text { highest quintile platelet nadir } \\
\text { gestational age } \\
\text { antenatal betamethasone } \\
\text { preeclampsia } \\
\text { respiratory distress syndrome } \\
\text { fluid intake }\end{array}$ & $\begin{array}{l}0.73 \\
0.43 \\
0.84 \\
0.52 \\
0.37 \\
2.73 \\
1.09\end{array}$ & $\begin{array}{r}0.55-0.98 \\
0.2-0.91 \\
0.70-0.99 \\
0.34-0.81 \\
0.14-0.99 \\
1.37-5.40 \\
1.00-1.19\end{array}$ \\
\hline Dizdar [9] & $\begin{array}{l}\text { platelet count }<150 \times 10^{9} / 1 \\
\text { platelet distribution width }>17 \\
\text { respiratory distress syndrome }\end{array}$ & $\begin{array}{l}2.083 \\
3.030 \\
2.534\end{array}$ & $\begin{array}{l}1.252-3.465 \\
1.571-5.847 \\
1.602-4.009\end{array}$ \\
\hline Sallmon [13] & $\begin{array}{l}\text { male sex } \\
\text { sepsis } \\
\text { gestational age }\end{array}$ & $\begin{array}{c}1.64 \\
2.82 \\
\text { not shown }\end{array}$ & $\begin{array}{l}1.32-2.04^{\mathrm{a}} \\
1.47-5.40^{\mathrm{a}}\end{array}$ \\
\hline Dani $[10]$ & $\begin{array}{l}\text { platelet count }<100 \times 10^{9} / 1 \\
\text { gestational age }\end{array}$ & $\begin{array}{l}4.50 \\
1.25\end{array}$ & $\begin{array}{l}1.39-14.61 \\
1.12-1.39\end{array}$ \\
\hline Bas-Suárez [15] & $\begin{array}{l}\text { gestational age } \\
\text { respiratory distress syndrome } \\
\text { arterial hypotension }\end{array}$ & $\begin{array}{l}0.778 \\
5.19 \\
2.99\end{array}$ & $\begin{array}{r}0.633-0.951 \\
1.76-15.27 \\
1.338-6.721\end{array}$ \\
\hline
\end{tabular}

data. DerSimonian and Laird random-effect models were used to derive random-effect estimates and 95\% CI for all outcomes. To identify any study that may have exerted a disproportionate influence on the summary effect, we deleted studies one at a time. Heterogeneity was assessed with the Q statistic and quantified using the $\mathrm{I}^{2}$ statistic. Because of the small number of studies, a funnel plot analysis to assess publication bias was not conducted. Meta-regression, using random effects (method of moments estimator), was performed to explore the following sources of heterogeneity in the relationship between PDA/SPDA and platelet counts: number of patients, cohort mean or median gestational age and birth weight, percent males, rate of PDA/SPDA, range of days in which platelet counts were assessed, thrombocytopenia rate, and year of publication. A p value less than 0.05 ( 0.10 for heterogeneity) was considered statistically significant. The study is reported according to the PRISMA checklist [17].

\section{Results}

We identified 31 potentially relevant studies through electronic and hand searches. After careful review, 8 full articles [7, 9, 10, 12-15, 18], 1 letter to the editor [11], and 1 abstract [19] were eligible for the meta-analysis. An additional unpublished cohort of 126 preterm infants was included in the meta-analysis. The infants in this cohort had been enrolled into a multicenter study, the Carbamoyl Phosphate Synthetase (CPS) Polymorphisms as Risk Factor for Necrotizing Enterocolitis (NCT00554866), for which the patient inclusion criteria were gestational age $\leq 30$ weeks and birth weight $\leq 1,500 \mathrm{~g}[20,21]$. Data on platelet counts of these patients were collected by two investigators (G.C. and L.v.Z.). The main characteristics of the studies are shown in table 1 . All the studies were cohort studies and only one [18] was prospective. Each study was allocated more than 6 NOS stars.

From the included studies, 4 [11, 12, 18, 19] compared infants with and without PDA, i.e. infants with a small PDA were included in the PDA group. Four studies [9, $10,14,15]$ compared infants with and without SPDA, i.e. infants with a small PDA were included in the non-SPDA group. Finally, 2 studies $[7,13]$ and the CPS cohort provided data on closed DA, small PDA, and SPDA. We included these 2 studies in both the comparison of PDA versus non-PDA and the comparison of SPDA versus non-SPDA. The risk factors for PDA/SPDA identified by multivariable analysis in the different studies are shown in table 2. 


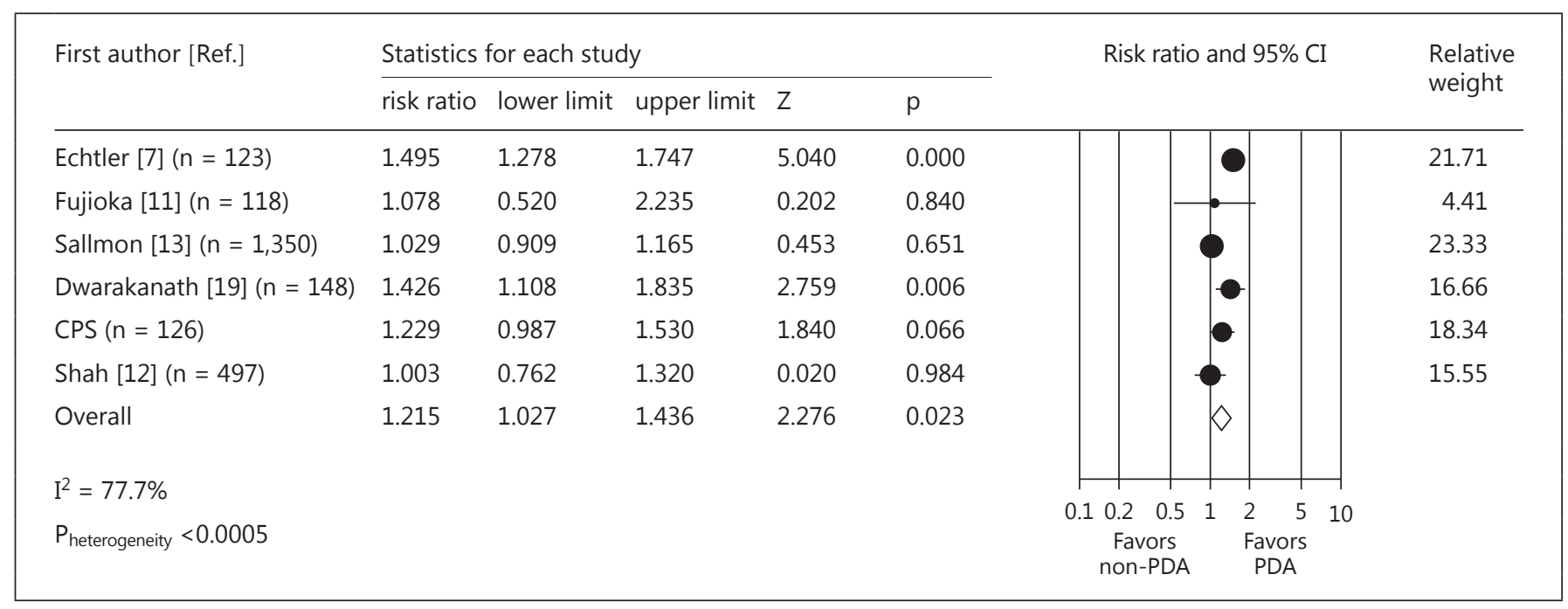

Fig. 1. Forest plot for studies examining the effect of platelet counts below $150 \times 10^{9} / 1$ in the first day(s) of life on PDA. Risk ratio $>1$ indicates increased risk of PDA. The data of Shah et al. [12] were not reported in the article but provided by the authors.

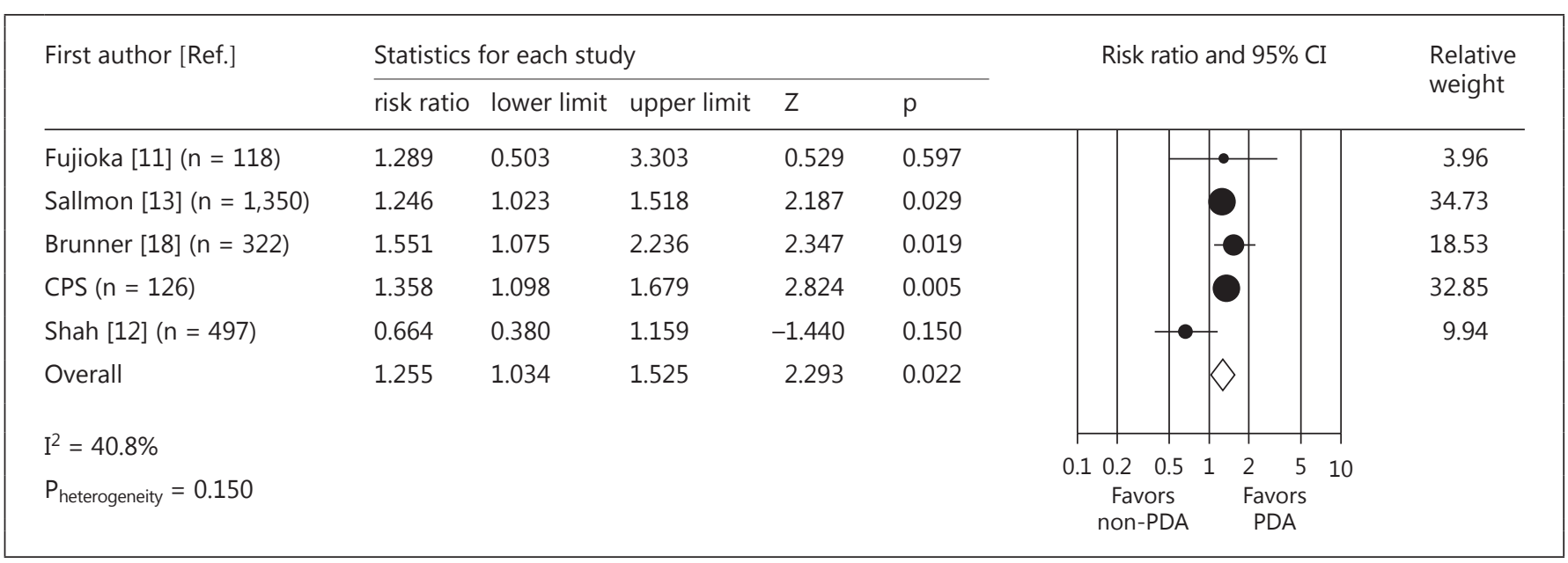

Fig. 2. Forest plot for studies examining the effect of platelet counts below $100 \times 10^{9} / 1$ in the first day(s) of life on PDA. Risk ratio $>1$ indicates increased risk of PDA. The study of Brunner et al. [18] reported the PDA rate in infants with platelet counts above $100 \times 10^{9} / 1$ and between 50 and $100 \times 10^{9} / 1$. The data of Shah et al. [12] and Fujioka et al. [11] were not reported in the articles but provided by the authors.

\section{Meta-Analysis}

Data on the rate of PDA in infants with platelet counts above or below $150 \times 10^{9} / 1$ were available from 6 cohorts (fig. 1). There was a significant positive association between PDA and platelet counts below $150 \times 10^{9} / 1$. In sensitivity analyses, excluding one study at a time, the summary RR ranged from 1.138 (95\% CI: 0.991-1.3067, $\mathrm{p}=$ 0.067), when the study of Echtler et al. [7] was excluded, to 1.291 (95\% CI: $1.106-1.507, \mathrm{p}=0.001)$, when the study of Sallmon et al. [13] was excluded. Data on the rate of PDA in infants with platelet counts above or below $100 \times$ $10^{9} / 1$ were available from 5 cohorts (fig. 2 ). There was a significant positive association between PDA and platelet counts below $100 \times 10^{9} / 1$. In sensitivity analyses, excluding one study at a time, the summary RR ranged from 1.220 (95\% CI: $0.886-1.681, \mathrm{p}=0.223$ ), when the study of 


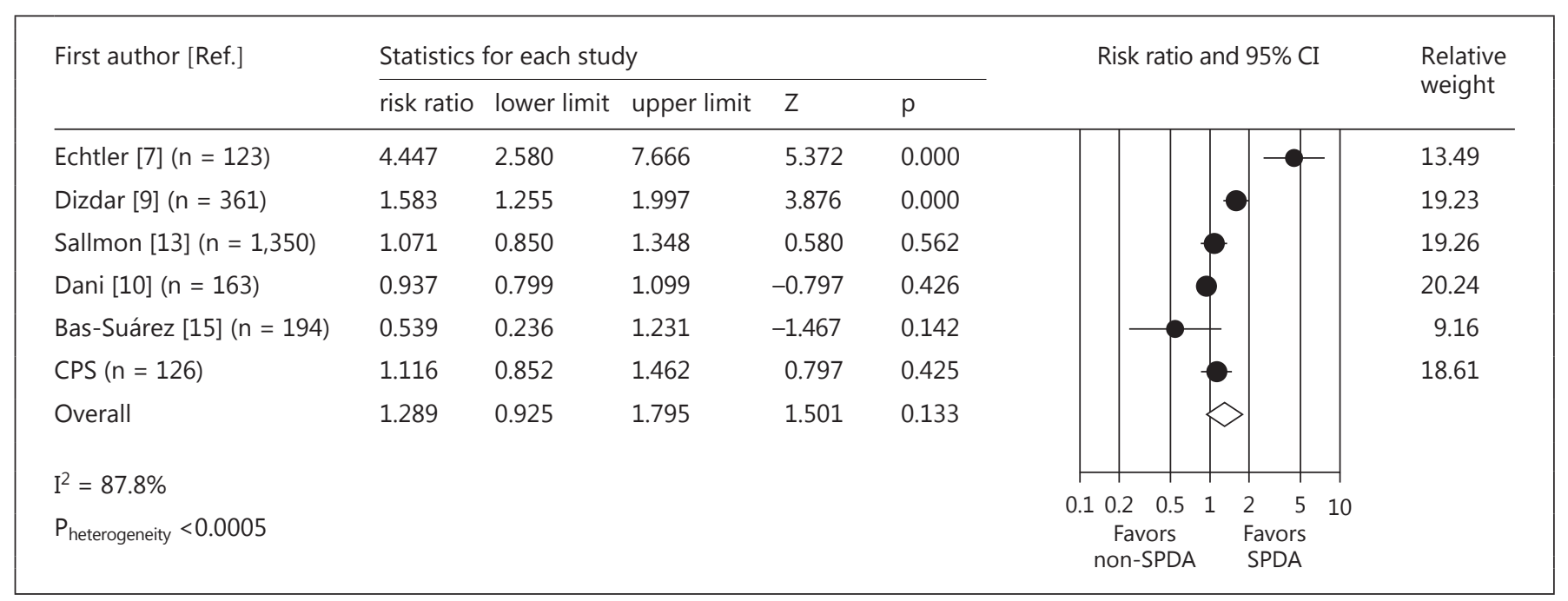

Fig. 3. Forest plot for studies examining the effect of platelet counts below $150 \times 10^{9} / 1$ in the first day(s) of life on SPDA. Risk ratio $>1$ indicates increased risk of SPDA. The data of Dani et al. [10] were not reported in the article but provided by the authors.

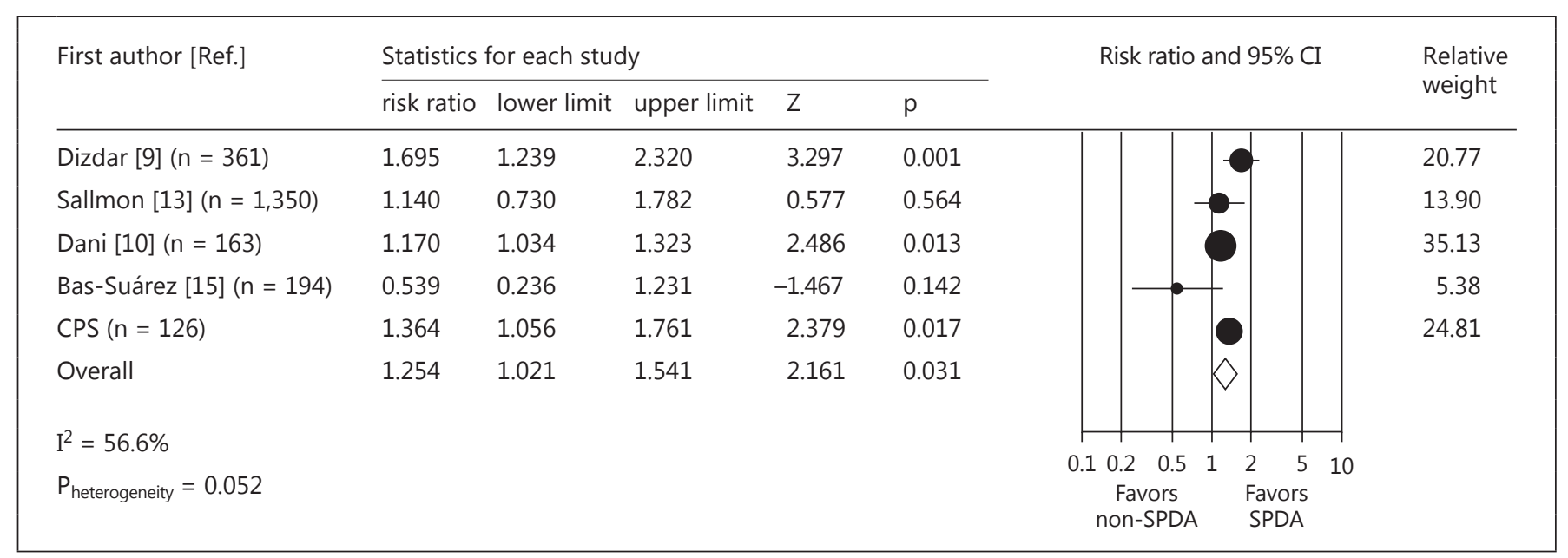

Fig. 4. Forest plot for studies examining the effect of platelet counts below $100 \times 10^{9} / 1$ in the first days of life on SPDA. Risk ratio $>1$ indicates increased risk of SPDA. The data of Dizdar et al. [9] and Dani et al. [10] were not reported in the articles but provided by the authors.

Sallmon et al. [13] was excluded, to 1.327 (95\% CI: 1.162$1.516, \mathrm{p}<0.001$ ), when the study of Shah et al. [12] was excluded. Data on the rate of PDA in infants with platelet counts above or below $50 \times 10^{9} / 1$ were available from 3 cohorts [12, 13 and CPS]. Meta-analysis could not detect a significant association between PDA and platelet counts below $50 \times 10^{9} / \mathrm{l}(\mathrm{RR}=1.072,95 \% \mathrm{CI}: 0.787-1.459, \mathrm{Z}=$ $0.441, \mathrm{p}=0.659)$. Mean (SD) platelet counts in infants with and without PDA were available from 3 cohorts [11, 12 and CPS]. The pooled standard difference (no-PDA minus PDA) in means was not statistically significant $\left(-6.67 \times 10^{9}, 95 \%\right.$ CI: -46.74 to $\left.-12.98, \mathrm{p}=0.754\right)$. When the CPS cohort was removed from the analysis, the pooled standard difference in means became $-29.86 \times 10^{9}(95 \%$ CI: -46.74 to $-12.98, \mathrm{p}=0.001$ ). 
Fig. 5. Random-effects (methods of moments) meta-regression analysis of the relation between birth weight (a) and gestational age (b) and risk of PDA with platelet counts below $100 \times 10^{9} / 1$ in the first day(s) of life.

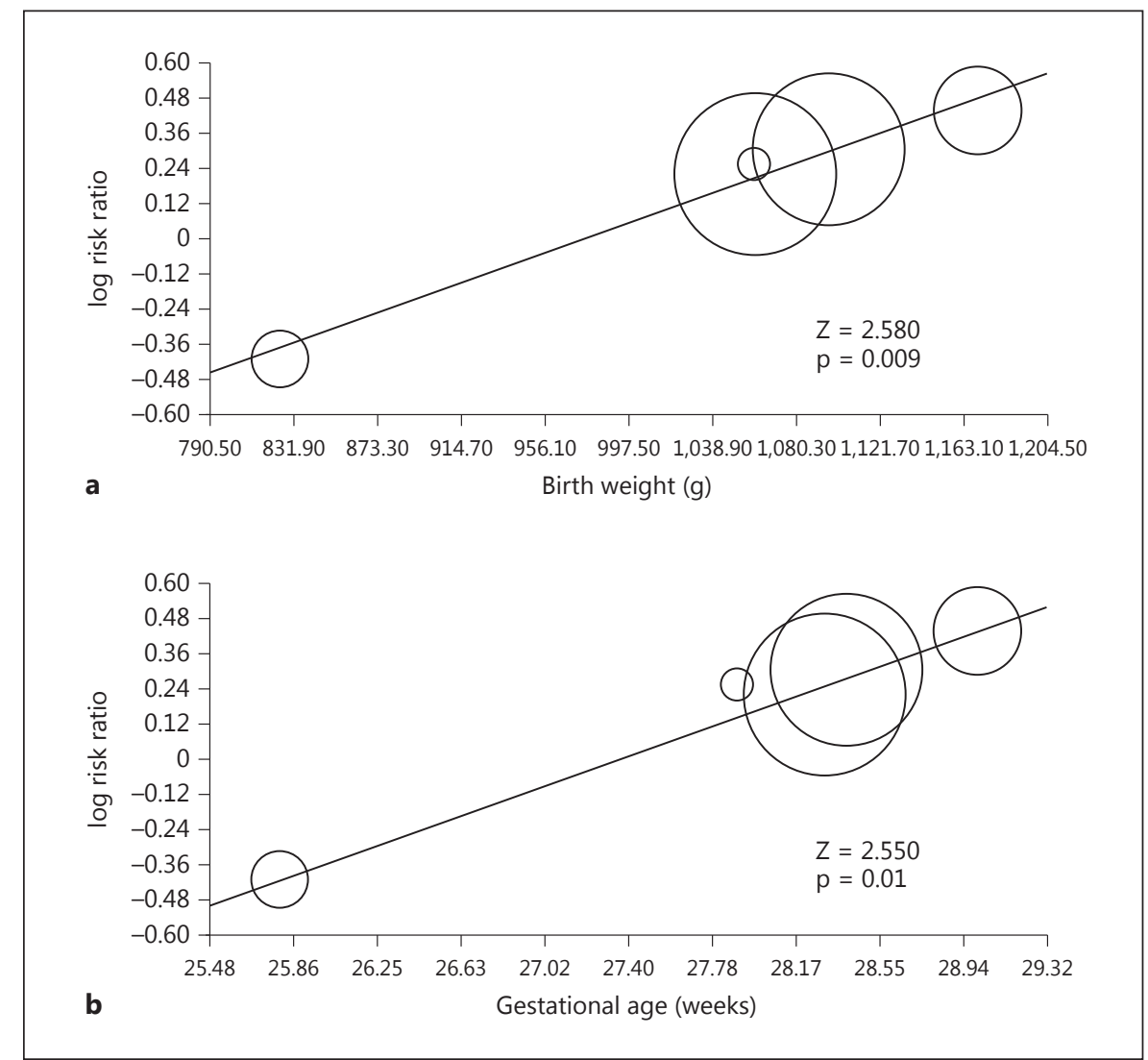

Data on the rate of SPDA in infants with platelet counts above or below $150 \times 10^{9} / 1$ were available from 6 cohorts (fig. 3). Meta-analysis could not detect a significant association between SPDA and platelet counts below $150 \times$ $10^{9} /$. In sensitivity analyses, excluding one study at a time, the summary RR ranged from 1.093 (95\% CI: $0.863-$ $1.383, \mathrm{p}=0.460)$, when the study of Echtler et al. [7] was excluded, to 1.404 (95\% CI: 0.998-1.977, $\mathrm{p}=0.052)$, when the study of Bas-Suárez et al. [15] was excluded. Data on the rate of SPDA in infants with platelet counts above or below $100 \times 10^{9} / 1$ were available from 5 cohorts (fig. 4). There was a significant positive association between SPDA and platelet counts below $100 \times 10^{9} / 1$. In sensitivity analyses, excluding one study at a time, the summary RR ranged from 1.177 (95\% CI: 0.979-1.414, $\mathrm{p}=0.082$ ), when the study of Dizdar et al. [9] was excluded, to 1.302 (95\% CI: $1.100-1.541, \mathrm{p}=0.002$ ), when the study of BasSuárez et al. [15] was excluded. Data on the rate of SPDA in infants with platelet counts above or below $50 \times 10^{9} / 1$ were available from 3 cohorts [12, 13 and CPS]. Metaanalysis could not detect a significant association between SPDA and platelet counts below $50 \times 10^{9} / 1(\mathrm{RR}=1.123$,
95\% CI: 0.717-1.757, $\mathrm{Z}=0.506, \mathrm{p}=0.613$ ). Mean (SD) platelet counts in infants with and without SPDA were available from 5 cohorts [9, 10, 14, 15 and CPS]. The pooled standard difference (no-SPDA minus SPDA) in means was not statistically significant $\left(11.69 \times 10^{9}, 95 \%\right.$ CI: -16.23 to $39.62, \mathrm{p}=0.412$ ).

Random-effects meta-regression analysis showed a significant positive correlation between mean gestational age (fig. 5a) and mean birth weight (fig. 5b) of the infants included in each study and risk of PDA when platelet count was below $100 \times 10^{9} / 1$. Thus, studies with more mature or larger infants showed higher RRs. In contrast, the studies which included a higher number of infants showed significantly lower risk of PDA with platelets below $150 \times$ $10^{9} / 1(\mathrm{Z}=-2.460, \mathrm{p}<0.014)$, and the studies including a higher percentage of males showed significantly lower RRs for SPDA when the platelet count was below $100 \times$ $10^{9} / 1(\mathrm{Z}=-1.976, \mathrm{p}=0.048)$. Meta-regression analyses did not show any significant effect of publication year, rate of $\mathrm{PDA} / \mathrm{SPDA}$, or rate of thrombocytopenia in the results of the meta-analysis. The range of postnatal age when platelet count was assessed (1-3 days; table 1) did 
not correlate with the incidence of platelet counts below $150 \times 10^{9} / 1$ (Spearman's correlation coefficient, $\rho_{\mathrm{s}}=$ $0.4276, \mathrm{p}=0.2499)$ or $100 \times 10^{9} / 1\left(\rho_{s}=0.2951, \mathrm{p}=0.4366\right)$ and random-effects meta-regression analysis did not show any significant effect of this range in the results of the meta-analysis.

\section{Discussion}

Our meta-analysis, which combines data from 11 study cohorts (3,479 preterm infants), shows that a low platelet count in the first day(s) of life is a modest but significant risk factor for PDA/SPDA. However, the low robustness of the association and the high degree of statistical heterogeneity among studies suggest that the link between platelet counts and DA closure might not be clinically relevant.

Term infants with conditions characterized by altered platelet number or function, such as Wiskott-Aldrich syndrome, alloimmune thrombocytopenia, or Glanzmann thrombasthenia, do not show an increased incidence of PDA [8, 22-24]. This argument has been used to question whether the findings of thrombotic closure of the mouse DA by Echtler et al. [7] can be extrapolated to humans [8]. It is important to note that in the full-term human newborn, postnatal DA constriction leads to narrowing of the lumen and compression of vasa vasorum, resulting in a hypoxic stimulus within the vessel wall. This hypoxia is necessary for DA remodeling and permanent anatomic closure $[8,25,26]$. The very preterm human DA and the term mouse DA are thin vessels and lack vasa vasorum. Therefore, they can still extract sufficient oxygen from residual luminal blood even when the DA is constricted $[8,25,26]$. Thus, thrombotic luminal occlusion might may play a significant role in the very preterm human DA, as it does in the mouse. However, as an argument against this hypothesis, we found a positive correlation between the maturity of the study infants and the association between PDA and low platelet counts (fig. 5).

One of the main difficulties in understanding the relationship between thrombocytopenia and PDA is the lack of agreement among neonatologists as to what defines these clinical entities. It is not clear whether the definition of neonatal thrombocytopenia as a platelet count $<150 \times$ $10^{9} / 1$ is applicable to very preterm infants $[27,28]$. In a large population study involving 47,291 neonates, the 5 th percentile of all platelet counts for infants $<32$ weeks of gestation was found to be $104 \times 10^{9} / 1$ [29]. In addition, the clinical relevance of mild $\left(100-150 \times 10^{9} / 1\right)$ or even mod- erate $\left(50-100 \times 10^{9} / 1\right)$ thrombocytopenia in premature infants is still unclear [28]. In the only prospective randomized trial to address this issue, investigators found that platelet transfusions in the setting of mild-to-moderate thrombocytopenia did not alter the incidence of PDA in preterm infants or other short-term outcomes [30].

The definition of PDA is also under debate. Clear evidence is lacking for or against many of the current approaches to a PDA in preterm infants. These uncertainties have resulted in different definitions of what investigators have called 'significant PDA', i.e. one that causes symptoms or is worthy of treatment $[3,4,31,32]$. We noted marked differences in the rates of PDA/SPDA reported in the studies included in our meta-analysis (table 1). This may reflect differences in the criteria used to define a PDA as clinically and/or hemodynamically significant [32]. However, meta-regression analysis showed no significant impact of the individual rates of PDA/ SPDA on the results of the meta-analysis.

The majority of the studies included in our meta-analysis were retrospective. As a result, important risk factors might not have been accurately identified or recorded [33] and the results may be confused by the timing of assessment of platelet counts and PDA. As an example of this, the platelet counts were generally done at the discretion of healthcare providers and not at a fixed interval. Therefore, the rate of thrombocytopenia in the more stable patients could have been underestimated. In addition, the range of days in which platelet counts were determined varied between 1 and 3 . It should be noted that the majority of preterm neonates who ultimately develop thrombocytopenia during the first week of life have either a low-normal platelet count $\left(150-200 \times 10^{9} / 1\right)$ or mild thrombocytopenia at birth [34]. Over the next several days, the platelet count falls, reaching a nadir on day $4-5$, before recovering to $>150 \times 10^{9} / 1$ by $7-10$ days. The relationship between the time of thrombocytopenia nadir and time of PDA closure is important since only $10-15 \%$ of preterm infants $<28$ weeks of gestation close their PDA between days 1 and 3; whereas, 30\% close their PDA by day $7[2,3]$. Only the studies of Shah et al. [12] and BasSuárez et al. [15] reported platelet counts after the third day of life, and they did not observe a relationship between low platelet counts on days 3-7 and PDA/SPDA.

It is also unclear whether any potential relationship between PDA and thrombocytopenia is really with thrombocytopenia itself or with some of its etiologies, such as intrauterine growth retardation or sepsis [34], which could affect DA closure. Rather than being responsible for PDA, it has been suggested that platelet counts 
are merely a surrogate marker of clinical maturity and stability [12]. In the study by Shah et al. [12], the infants whose platelet counts never fell below the highest quintile $\left(>230 \times 10^{9} / \mathrm{l}\right)$ had the lowest incidence of PDA.

In conclusion, the present meta-analysis reveals a marginal but significant association between low platelet counts in the first day(s) of life and PDA/SPDA in very preterm infants. This association needs to be confirmed in prospective studies. In addition, any relationship between association and causation needs to be determined. It has been proposed that impaired platelet function, due to immaturity and critical illness, rather than platelet number, may contribute to PDA $[13,35]$. Therefore, future studies should take into account not only the number but also the function of platelets [35]. However, platelet function tests require a large volume of blood and poorly simulate in vivo primary hemostasis [36]. Finally, further studies are warranted to evaluate the role of platelet counts in the response of PDA to treatment. Paradoxically, despite their known inhibitory effects on platelet activation in vitro [7], both indomethacin and ibuprofen are effective at inducing PDA closure. Interestingly, Boo et al. [37] and - very recently - Ahamed et al. [38] reported an association between low platelet counts before starting indomethacin treatment and lack of response to the therapy. Nevertheless, this finding has not been confirmed in other studies [12, 15].

\section{Acknowledgments}

We thank I. Morioka, E.A. Dizdar, and C. Dani for kindly providing additional data and clarifications on their studies. This work was partially supported by a grant from the Fundación Canaria del Colegio de Médicos de Las Palmas.

\section{Disclosure Statement}

The authors report no competing interests.

\section{References}

1 Stoller JZ, DeMauro SB, Dagle JM, Reese J: Current perspectives on pathobiology of the ductus arteriosus. J Clin Exp Cardiolog 2012; 8:pii: S8-001.

2 Clyman RI: Mechanisms regulating the ductus arteriosus. Biol Neonate 2006;89:330-335.

3 Heuchan AM, Clyman RI: Managing the patent ductus arteriosus: current treatment options. Arch Dis Child Fetal Neonatal Ed 2014; 99:F431-F436.

4 Gudmundsdottir A, Johansson S, Hakansson S, Norman M, Kallen K, Bonamy AK: Timing of pharmacological treatment for patent ductus arteriosus and risk of secondary surgery, death or bronchopulmonary dysplasia: a population-based cohort study of extremely preterm infants. Neonatology 2015;107:87-92.

-5 Oncel MY, Yurttutan S, Degirmencioglu H, Uras N, Altug N, Erdeve O, Dilmen U: Intravenous paracetamol treatment in the management of patent ductus arteriosus in extremely low birth weight infants. Neonatology 2013;103:166-169.

6 Khositseth A, Muangyod N, Nuntnarumit P: Perfusion index as a diagnostic tool for patent ductus arteriosus in preterm infants. Neonatology 2013;104:250-254.

-7 Echtler K, Stark K, Lorenz M, Kerstan S, Walch A, Jennen L, Rudelius M, Seidl S, Kremmer E, Emambokus NR, von Bruehl ML, Frampton J, Isermann B, Genzel-Boroviczeny O, Schreiber C, Mehilli J, Kastrati A, Schwaiger M, Shivdasani RA, Massberg S:
Platelets contribute to postnatal occlusion of the ductus arteriosus. Nat Med 2010;16:7582.

8 Clyman R, Chemtob S: Vessel remodeling in the newborn: platelets fill the gap. Nat Med 2010;16:33-35.

-9 Dizdar AE, Ozdemir R, Nur Sari F, Yurttutan S, Gokmen T, Erdeve O, Emre Canpolat F, Uras N, Suna Oguz S, Dilmen U: Low platelet count is associated with ductus arteriosus patency in preterm newborns. Early Hum Dev 2012;88:813-816.

10 Dani C, Poggi C, Fontanelli G: Relationship between platelet count and volume and spontaneous and pharmacological closure of ductus arteriosus in preterm infants. Am J Perinatol 2013;30:359-364.

11 Fujioka K, Morioka I, Miwa A, Morikawa S, Shibata A, Yokoyama N, Matsuo M: Does thrombocytopenia contribute to patent ductus arteriosus? Nat Med 2011;17:29-30; author reply 30-21.

-12 Shah NA, Hills NK, Waleh N, McCurnin D, Seidner S, Chemtob S, Clyman R: Relationship between circulating platelet counts and ductus arteriosus patency after indomethacin treatment. J Pediatr 2011;158:919-923.e1-e2.

13 Sallmon H, Weber SC, Huning B, Stein A, Horn PA, Metze BC, Dame C, Bührer C, Felderhoff-Müser U, Hansmann G, Koehne P: Thrombocytopenia in the first $24 \mathrm{~h}$ after birth and incidence of patent ductus arteriosus. Pediatrics 2012;130:e623-e630.
14 Chen YY, Wang HP, Chang JT, Chiou YH, Huang YF, Hsieh KS; Taiwan Premature Infant Development Collaborative Study Group: Perinatal factors in patent ductus arteriosus in very low-birthweight infants. Pediatr Int 2014;56:72-76.

15 Bas-Suárez MP, Gonzalez-Luis GE, Saavedra $P$, Villamor E: Platelet counts in the first seven days of life and patent ductus arteriosus in preterm very low-birth-weight infants. Neonatology 2014;106:188-194.

16 Wells GA, Shea B, O'Connell D, Peterson J, Welch V, Losos M: The Newcastle-Ottawa Scale (NOS) for assessing the quality of nonrandomized studies in meta-analyses. http:// www.ohri.ca/programs/clinical_epidemiology/oxford.htm (accessed October 2014).

17 Moher D, Liberati A, Tetzlaff J, Altman DG; PRISMA Group: Preferred reporting items for systematic reviews and meta-analyses: the PRISMA statement. BMJ 2009;339: b2535.

18 Brunner B, Hoeck M, Schermer E, Streif W, Kiechl-Kohlendorfer U: Patent ductus arteriosus, low platelets, cyclooxygenase inhibitors, and intraventricular hemorrhage in very low birth weight preterm infants. J Pediatr 2013;163:23-28.

19 Dwarakanath K, Dereddy N, Chabra D, Schabacker C, Calo J, Parton L: Spontaneous and pharmacological closure of PDAs in ELBW infants is influenced by thrombocytopenia (abstract). E-PAS 21. 2011. 
20 Moonen RM, Huizing MJ, Cavallaro G, Gonzalez-Luis GE, Bas-Suárez P, Bakker JA, Villamor E: Plasma levels of dimethylarginines in preterm very low birth weight neonates: its relation with perinatal factors and short-term outcome. Int J Mol Sci 2015;16:19-39.

21 Moonen RM, Reyes I, Cavallaro G, GonzalezLuis G, Bakker JA, Villamor E: The T1405N carbamoyl phosphate synthetase polymorphism does not affect plasma arginine concentrations in preterm infants. PLoS One 2010;5:e10792.

22 Awidi AS: Delivery of infants with Glanzmann thrombasthenia and subsequent blood transfusion requirements: a follow-up of 39 patients. Am J Hematol 1992;40:1-4.

23 Bussel JB, Zacharoulis S, Kramer K, McFarland JG, Pauliny J, Kaplan C: Clinical and diagnostic comparison of neonatal alloimmune thrombocytopenia to non-immune cases of thrombocytopenia. Pediatr Blood Cancer 2005;45:176-183.

24 Ochs HD, Filipovich AH, Veys P, Cowan MJ, Kapoor N: Wiskott-Aldrich syndrome: diagnosis, clinical and laboratory manifestations, and treatment. Biol Blood Marrow Transplant 2009; 15:84-90.

25 Goldbarg S, Quinn T, Waleh N, Roman C, Liu BM, Mauray F, Clyman RI: Effects of hypoxia, hypoglycemia, and muscle shortening on cell death in the sheep ductus arteriosus. Pediatr Res 2003;54:204-211.

26 Kajino H, Goldbarg S, Roman C, Liu BM, Mauray F, Chen YQ, Takahashi Y, Koch CJ, Clyman RI: Vasa vasorum hypoperfusion is responsible for medial hypoxia and anatomic remodeling in the newborn lamb ductus arteriosus. Pediatr Res 2002;51:228-235.

27 Chakravorty S, Roberts I: How I manage neonatal thrombocytopenia. Br J Haematol 2012; 156:155-162.

28 Sola-Visner M: Platelets in the neonatal period: developmental differences in platelet production, function, and hemostasis and the potential impact of therapies. Hematology Am Soc $\mathrm{He}-$ matol Educ Program 2012;2012:506-511.

29 Wiedmeier SE, Henry E, Sola-Visner MC, Christensen RD: Platelet reference ranges for neonates, defined using data from over 47,000 patients in a multihospital healthcare system. J Perinatol 2009;29:130-136.

30 Andrew M, Vegh P, Caco C, Kirpalani H, Jefferies A, Ohlsson A, Watts J, Saigal S, Milner $\mathrm{R}$, Wang E: A randomized, controlled trial of platelet transfusions in thrombocytopenic premature infants. J Pediatr 1993;123:285291.

31 Clyman R: Early treatment versus delayed conservative treatment of the patent ductus arteriosus (PDA:TOLERATE). https://clin-
icaltrials.gov/ct2/show/NCT01958320 (accessed March 2015)

2 Zonnenberg I, de Waal K: The definition of a haemodynamic significant duct in randomized controlled trials: a systematic literature review. Acta Paediatr 2012;101:247-251.

33 Sedgwick P: Retrospective cohort studies: advantages and disadvantages. BMJ 2014; 348:g1072.

34 Murray NA: Evaluation and treatment of thrombocytopenia in the neonatal intensive care unit. Acta Paediatr Suppl 2002;91:74-81.

35 Sallmon H, Weber SC, von Gise A, Koehne P, Hansmann G: Ductal closure in neonates: a developmental perspective on platelet-endothelial interactions. Blood Coagul Fibrinolysis 2011;22:242-244.

36 Haley KM, Recht M, McCarty OJ: Neonatal platelets: mediators of primary hemostasis in the developing hemostatic system. Pediatr Res 2014;76:230-237.

37 Boo NY, Mohd-Amin I, Bilkis AA, YongJunina F: Predictors of failed closure of patent ductus arteriosus with indomethacin. Singapore Med J 2006;47:763-768.

38 Ahamed MF, Verma P, Lee S, Vega M, Wang D, Kim M, Fuloria M: Predictors of successful closure of patent ductus arteriosus with indomethacin. J Perinatol 2015, DOI: 10.1038/ jp.2015.33. 